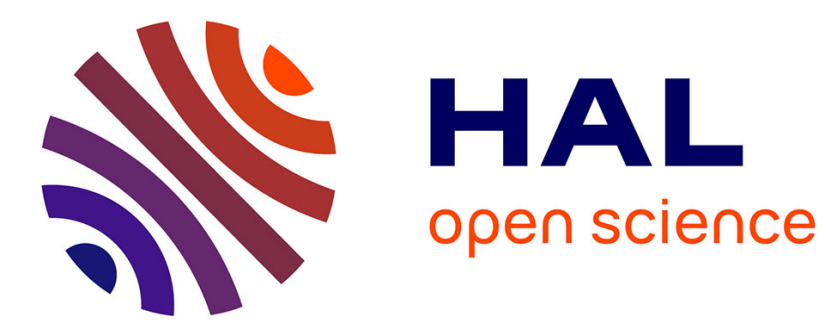

\title{
Correlation between ground motion and building response using Californian earthquake records
}

Matthieu Perrault, Philippe Gueguen

\section{To cite this version:}

Matthieu Perrault, Philippe Gueguen. Correlation between ground motion and building response using Californian earthquake records. Earthquake Spectra, 2015, 10.1193/062413EQS168M . hal-01356717

\section{HAL Id: hal-01356717 https://hal.science/hal-01356717}

Submitted on 26 Aug 2016

HAL is a multi-disciplinary open access archive for the deposit and dissemination of scientific research documents, whether they are published or not. The documents may come from teaching and research institutions in France or abroad, or from public or private research centers.
L'archive ouverte pluridisciplinaire HAL, est destinée au dépôt et à la diffusion de documents scientifiques de niveau recherche, publiés ou non, émanant des établissements d'enseignement et de recherche français ou étrangers, des laboratoires publics ou privés. 


\title{
Correlation between ground motion and building response using Californian earthquake records
}

\section{Matthieu Perrault ${ }^{\text {a) }}$ and Philippe Guéguen ${ }^{\text {a) }}$}

\begin{abstract}
Using data from the California Strong Motion Instrumentation Program, we studied the relationship between building response and parameters describing the noxiousness of ground motion. According to vulnerability methods that use structural drift as damage criteria, we estimated the building response on the basis of the normalized relative roof displacement (NRRD), considered as damage criteria. The relationships between the NRRD and the intensity measures of the ground motion are developed using simulated annealing method. Grouping buildings by typology (defined according to their main construction material and height) reduces the variability of the building response. Furthermore, by combining IMs, the NRRD can be predicted more accurately by a Building Damage Prediction Equation. A functional form is thus proposed to estimate the NRRD for several building typologies, calibrated on the building responses recorded in California. This functional form can be used to obtain a fast and overall damage forecast after an earthquake.
\end{abstract}

\section{INTRODUCTION}

In seismic vulnerability assessment methods, such as Hazus (FEMA, 1999), the vulnerability of a building category can be studied by assessing fragility curves. By relating a probability of damage to a ground motion intensity measure (IM), such as peak ground acceleration (PGA) or displacement response spectra (Sd), these curves account for variability due to the building model definition, the threshold damage parameter and the IMs, considered as being the engineering demand parameters providing the best representation of the noxiousness of ground motion. The relation between building response and IM can be linked to the damage prediction when associated with damage state thresholds. For example, Hancock et al. (2008) proposed an equation relating earthquake parameters (magnitude, 
epicentral distance) and damage prediction. Luco (2002) defined two natures of IM: (1) an efficient IM defined as providing small variability of the conditional probability of damage (DM) given IM P(DM|IM); and (2) a sufficient IM defined as providing conditionally independent DM of the magnitude and distance. Coupled with real-time estimates of seismic ground motion (e.g., Wald et al., 1999; Worden et al., 2010), Wald et al. (2008) proposed a real-time assessment of expected damage for critical facilities. More recently, Krishnan et al. (2012) estimated damage for tall buildings present in a wide area by coupling ground motion predictions with a numerical analysis of building models. Most of these studies use numerical methods to model building response, and a "building-specific" prediction for a given scenario can provide accurate estimation of damage. However, numerical methods may require costly resources not suited for a global scale analysis. Moreover, they are often not fully representative of the response of existing buildings because of the lack of information and description of the structural design that finally require some assumptions (quality of the materials, boundary conditions, etc...).

Our study aims at assessing the correlation between efficient IMs according to the definition of Luco (2002) and building response using experimental data from a database of strong motions recorded in Californian buildings. From this database, the variability of building response is assessed through the normalized relative roof displacement (NRRD) and a combination of IMs is proposed as predictive equations of the expected response of building. These equations can be considered as a tentative of providing a building damage prediction equation (BDPE).

\section{DATABASE OF STRONG MOTION RECORDED WITHIN BUILDINGS}

The US Geological Survey (USGS) and the California Geological Survey (CGS) set up the Center for Engineering Strong Motion Data (CESMD) to provide earthquake recording data. An instrumentation program was launched in California in 1972 (CSMIP: California Strong Motion Instrumentation Program) to equip buildings, dams, bridges and empty fields with earthquake sensors. Only one set of earthquake data recorded in buildings was used in our study. These data include records of 115 ground motions from 234 buildings (Figure 1).

These buildings are mainly steel frame (114) or reinforced concrete structures (76). There are also 13 masonry buildings and 8 wooden structures. Data from buildings that were built

\footnotetext{
a) ISTerre, University of Grenoble, CNRS/IFSTTAR, France.
} 
or retrofitted with earthquake isolation systems (19) were not used in this study. In order to compare with Hazus' building classification, three height categories were considered: lowrise (LR), mid-rise (MR) and high-rise (HR) buildings, for buildings comprising 1 to 3 floors, 4 to 7 floors, and more than 8 floors, respectively. The LR class counts 70 buildings, the MR class 96 buildings and the HR class 68 buildings.

The entire database comprises 772 \{building/earthquake\} pairs, a pair representing a building in which at least one accelerogram was recorded. The corresponding magnitudeepicentral distance diagram is represented in Figure 1. Magnitude $\left(\mathrm{M}_{\mathrm{W}}\right.$ or $\mathrm{M}_{\mathrm{L}}$ as provided by the CESMD website) ranges from 3.5 to 7.2, including well-known earthquakes included such as the 02/09/1979 San-Fernando earthquake $\left(\mathrm{M}_{\mathrm{W}}=6.6\right)$, the 10/17/1989 Loma-Prieta earthquake $\left(\mathrm{M}_{\mathrm{W}}=6.9\right)$, the $06 / 28 / 1992$ Landers earthquake $\left(\mathrm{M}_{\mathrm{W}}=7.2\right)$ and the $01 / 17 / 1994$ Northridge earthquake $\left(\mathrm{M}_{\mathrm{W}}=6.5\right)$. The epicentral distances range from $2 \mathrm{~km}$ to $430 \mathrm{~km}$. Borzi et al. (2001) and Ambrasey et al. (2005) identified the engineering significance of earthquakes for $\mathrm{M}_{\mathrm{W}}>5$ and a source-to-distance less than $150 \mathrm{~km}$. Without additional parameters on magnitude and distance, the percentage of data respecting the magnitude $\left(\mathrm{M}_{\mathrm{L}}\right.$ or $\mathrm{M}_{\mathrm{W}}$ )/distance (epicentral) criteria is $40 \%$ (as noted on Figure 1).

The sensors are 1D accelerometers, with sampling frequency varying from $50 \mathrm{~Hz}$ to $200 \mathrm{~Hz}$. Velocities and displacements were computed from the acceleration records, by removing the trend and mean value and filtering with an acausal Butterworth filter with 4 poles between 0.1 and $25 \mathrm{~Hz}$ and one or two signal integrations. The $25 \mathrm{~Hz}$ cut-off frequency was selected for providing a homogenous database, respecting the Nyquist condition. The peak ground accelerations recorded range from 0.017 to $8.161 \mathrm{~m} / \mathrm{s}^{2}$, peak ground velocities from 0.001 to $1.119 \mathrm{~m} / \mathrm{s}$ and peak ground displacements from 0.003 to $26.740 \mathrm{~cm}$. 

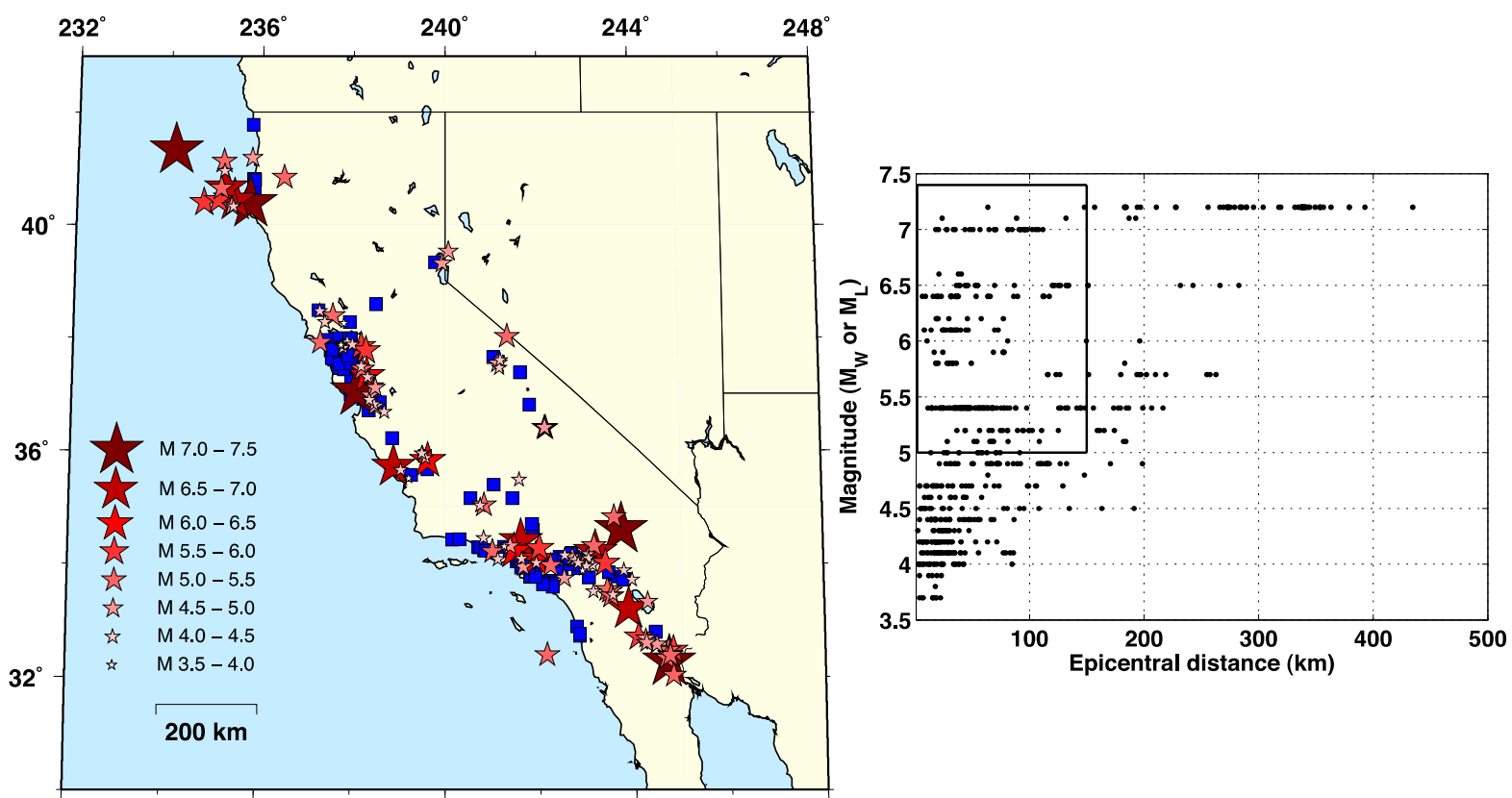

Figure 1. Left: Map of California showing building location (squares) and earthquake epicenters (stars) from the CSMIP database. Right: magnitude-distance diagram corresponding to the entire database. The black rectangle contains 306 data (on a total of 772 data), which correspond to the criteria: $\mathrm{M} \geq 5.0$ and $\mathrm{d} \leq 150 \mathrm{~km}$.

In order to increase the number of data used for the prediction of damage, we considered separately the two horizontal directions of the buildings, although they are not independent. Finally, we processed 772 pieces of data as described herein. First, considering the displacements at the top and ground floors, total relative displacement was computed and normalized with building height to obtain the Normalized Relative Roof Displacement (NRRD) considered herein as damage criterion. The correlation between damage and NRRD may be subject to caution but this parameter is easily computed with the available data in this study. Moreover, this value is a global parameter corresponding to the mean inter-storey drift observed during earthquakes and it can also be compared to the Hazus inter-storey drift limits (FEMA, 1999) given for several building typologies and four damage levels (slight, moderate, extensive and complete). The four damage states of the Hazus methodology are similar to those defined in EERI (1994), but for each Hazus building type based on the structural system. If the Hazus threshold is exceeded, a damage level is expected. In the following, we will deal with the variability between ground motion parameters and building response, considering NRRD as the damaged or undamaged criterion for characterizing building integrity. 


\section{INTENSITY MEASURES AND BUILDING RESPONSE}

The variability of building responses with respect to the ground motion parameter is analyzed by testing the relationship between NRRD and standard or specific IMs. Peak Ground Acceleration (PGA), Velocity (PGV) and Displacement (PGD) are computed from the acceleration, velocity and displacement time histories, corresponding to the maximum peaks. From the acceleration time history $a(t)$, the Arias Intensity (AI; Arias, 1970) and the Cumulative Absolute Velocity (CAV; EPRI, 1988) are defined as:

$$
\begin{aligned}
& A I=\frac{\pi}{2 g} \int_{0}^{t_{E}} a^{2}(t) d t \\
& C A V=\int_{0}^{t_{E}}|a(t)| d t
\end{aligned}
$$

where $t_{E}$ is the total duration of the recording. Two other definitions are derived from the original CAV definition:

$$
\begin{gathered}
C A V_{5}=\frac{\pi}{2 g} \int_{0}^{t_{E}} H(|a(t)|-0.05)|a(t)| d t \\
C A V_{\text {std }}=\sum_{i=1}^{N}\left(H\left(P G A_{i}-0.025\right) \int_{t_{i}}^{t_{i+1}}|a(t)| d t\right)
\end{gathered}
$$

where $\mathrm{N}$ is the number of consecutive $1 \mathrm{~s}$ intervals and $\mathrm{H}$ is the Heaviside function (i.e., zero for negative argument and one for positive arguments). $\mathrm{CAV}_{5}$ only takes into account amplitudes greater than $0.05 \mathrm{~m} / \mathrm{s}^{2}$, and $\mathrm{CAV}_{\text {std }}$ does not take into account $1 \mathrm{~s}$ intervals with amplitudes less than $0.025 \mathrm{~m} / \mathrm{s}^{2}$ (EPRI, 1991).

Additional IMs, such as spectral acceleration, velocity and displacement, are defined for a given frequency and damping ratio. Different solutions exist for extracting the frequency of existing buildings. Six frequency definitions are considered herein, using empirical relationships or signal processing of the recordings at the top of the structures (Figure 2):

(1) the frequency corresponding to the peak in the Fourier transform of the top recording, noted $\mathrm{f}_{\mathrm{FFT}}$;

(2) the frequency corresponding to pre-seismic behavior, noted $\mathrm{f}_{0, \mathrm{ST}}$, and evaluated from a time-frequency distribution at the beginning of the recording. When the top and the bottom recordings are synchronized, an S-transform (Stockwell et al., 1996) is performed on the relative displacement between the top and the bottom floors, as proposed by Todorovska and 
Trifunac (2007). If synchronization was not confirmed, the frequency assessment was carried out on the top acceleration recording, as suggested by Michel and Guéguen (2010). Frequency $f_{0, S T}$ corresponds to the value of the building frequency before the earthquake occurs. This frequency can be extracted directly from ambient vibrations, in the framework of identification surveys of modal properties for existing buildings, as developed by Michel et al. $(2011,2012)$.

(3) the frequency corresponding to the minimal value of the time-frequency distribution, noted $f_{\min , S T}$. Due to the opening and closing of pre-existing cracks, building frequency shifts during earthquakes, and the more the structure is damaged, the greater the frequency reduction (Todorovska and Trifunac, 2007; Michel and Guéguen, 2010; Michel et al., 2011).

(4) the frequency corresponding to post-seismic behavior, noted $f_{\text {end,ST, }}$ and evaluated from the time-frequency diagram at the end of the recording. A shift between the $f_{0, S T}$ and $f_{\text {end,ST }}$ frequencies provides information on the structural integrity of the building (e.g. Dunand et al., 2004; Clinton et al., 2006).

(5) the frequency corresponding to the empirical frequency $f_{\text {emp }}=10 / \mathrm{N}$, where $\mathrm{N}$ is the number of floors.

(6) the frequency corresponding to the European Eurocode 8 code (CEN, 2005) and the Canadian code (NBCC, 2005), and simplified, in term of periods, as: $\mathrm{T}=0.085 \mathrm{H}^{3 / 4}$ for steel structures, $\mathrm{T}=0.075 \mathrm{H}^{3 / 4}$ for $\mathrm{RC}$ structures, $\mathrm{T}=0.025 \mathrm{H}^{3 / 4}$ for masonry structures and $\mathrm{T}=\mathrm{N} / 10$ for the other structures. This frequency is noted $\mathrm{f}_{\text {emp,EC8}}$.

The damping ratio was obtained by computing the impulse response of the structure (Figure 2), corresponding to the inverse Fourier transform of the ratio between the top and the bottom recordings. The damping ratio is then assessed by applying the logarithmic decrement method to the impulse response function (Clough and Penzien, 1993) and is proportional to the width of the function at $-3 \mathrm{~dB}$. Some ratios present values exceeding $15 \%$. Higher values are expected with higher ground motions, but these values may come from the method, which may not be sufficiently robust. Perrault et al. (2013) showed the significant effect of the variation of damping values on fragility functions. Without additional information on the relevancy of this estimate, it is difficult to adopt other solution for setting damping values. However, for all buildings, the median value of the damping ratios is approximately equal to $5 \%$ (Figure 3), which corresponds to the standard value provided in 
the seismic codes. In spite of the large scatter of estimated damping, as observed in Figure 3, a constant value of $5 \%$ is assumed in this paper.

We first analyzed the ground motion parameter distributions and the NRRD distributions. We divided PGA in 5 classes of 150 pieces of the 772 building-earthquake pairs, removing extreme values, i.e. the 11 lowest values (from the minimum values $0.017 \mathrm{~m} / \mathrm{s}^{2}$ to $0.032 \mathrm{~m} / \mathrm{s}^{2}$ ) and the 11 highest values (above $4.0 \mathrm{~m} / \mathrm{s}^{2}$ ), and we plotted (Figure 4) the distribution of NRRD versus PGA. We observed that, for a uniform distribution of ground motion parameters, such as PGA or PGV, the NRRD follows a lognormal distribution, or a normal distribution in a logarithmic axis. Even if the fifth class corresponding to the strongest values lacks data to have a perfect uniform distribution of PGA, this figure confirms the log-normal distribution assumption, considering to represent the vulnerability of existing buildings through fragility curves, i.e. giving the probability to observe a certain level of damage (through NRRD for example) with respect to ground motion intensity (IMs) (e.g., FEMA, 1999; Milutinovic and Trendafiloski, 2003; McGuire, 2004; Calvi et al., 2006; Michel et al., 2012; Perrault et al., 2013). The same result is observed whatever the IM. Thus, in order to assess the variability of the building response due to ground motion variability, we introduce two functional forms between the IM and the structural response NRRD:

$$
\begin{gathered}
\ln (N R R D)=a+b \ln (I M)+\varepsilon \\
\ln (N R R D)=a+b \ln (I M)+c I M+\varepsilon
\end{gathered}
$$

where $a, b$ and $c$ are coefficients that will be adjusted on the basis of ground motion records and $\varepsilon$ corresponds to residual variability. The $\ln$ function corresponds to the natural logarithm.

\section{VARIABILITY OF BUILDING RESPONSE WITH STANDARD INTENSITY MEASURES}

We first worked on the standard IMs, considering the two functional forms for each IM (Figure 5). On this figure, we observe that PGV provides the smaller standard deviation ( $\sigma=0.88$ for the two functional forms) while PGA is less efficient, suggesting that earthquake damage statistics give a much closer correlation with the PGV than with the peak ground acceleration, already reported by Lesueur et al. (2013) and Wu et al. (2002, 2003). All 

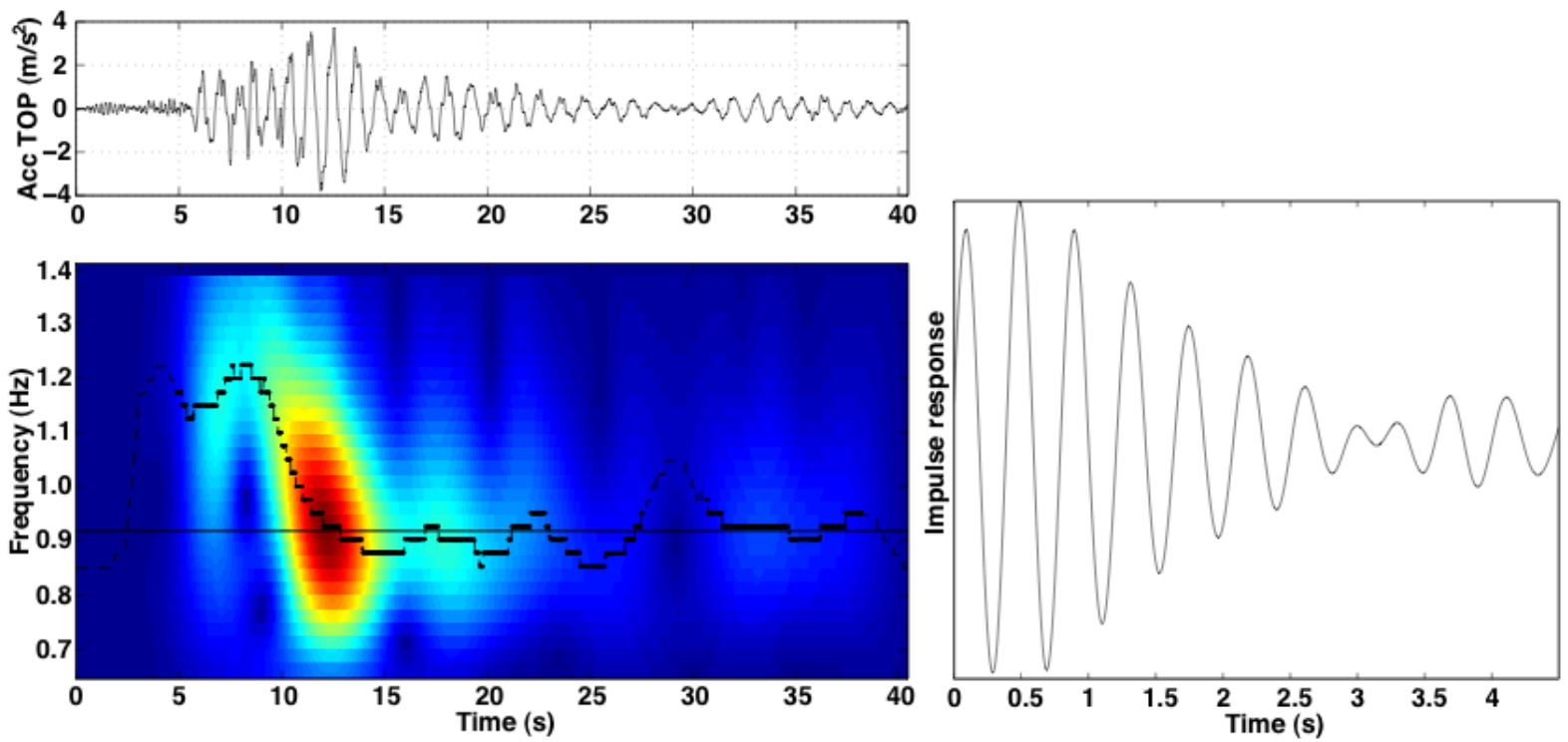

Figure 2. Left: Example of an S-transform (Stockwell et al., 1996) performed on the 1971 San Fernando earthquake recording at the top floor of the Millikan Library building. Right: Impulse response used to assess the damping ratio.

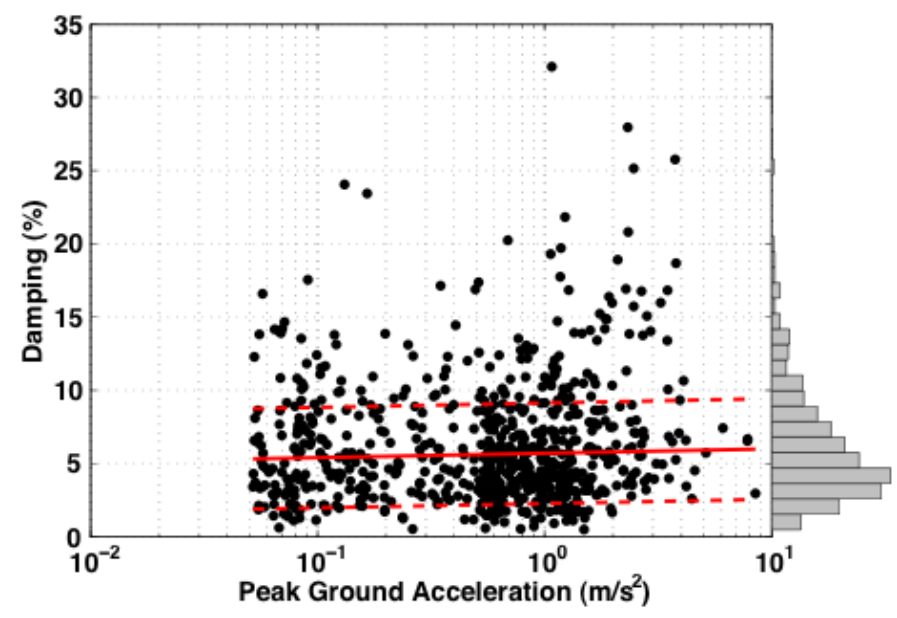

Figure 3. Damping ratios of the Californian buildings assessed by applying the logarithmic decrement method to each building impulse response.

results are presented in Table 1, where only the standard deviations are given.

As expected, the second functional form (Equation 6) provides smaller variabilities, even if the differences compared to the variabilities provided by Equation 5 are not significant (see Table 1) (see Electronic Supplements). This is also confirmed in Figure 5, comparing the two functional forms (Equations 5 and 6) considered PGA and PGV as IMs. However, the $c$ IM term in Equation 6 causes a difference in the slope of the curves, as seen in the Figure 5 for the higher value of PGV. This is expected for the greater IM, which may be representative of the non-linear behavior of the structural response. If we consider all the buildings, we observe significant variabilities, which are all greater than 0.88 whatever the IM used and for 


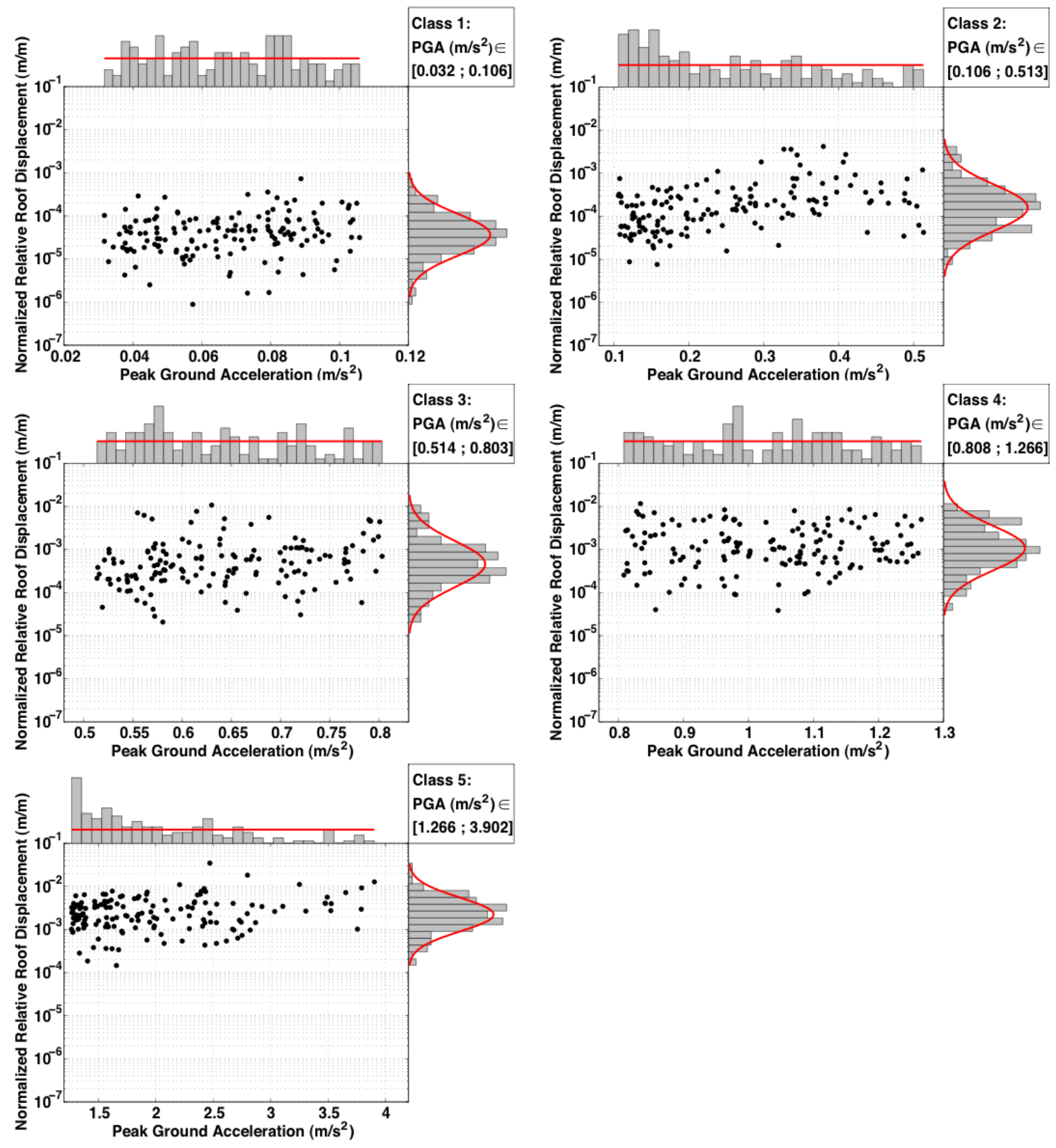

Figure 4. NRRD distributions according to PGA distributions for five categories of PGA (from left to right, and from top to bottom): [0.032;0.106], [0.106;0.513], [0.514;0.803], [0.808; 1.266] and $[1.266 ; 3.902] \mathrm{m} / \mathrm{s}^{2}$. Each category includes 150 pieces of data from the Californian buildings database.

the two functional forms. This results in a factor $\exp (2 \sigma) \approx 6$ between the ratios of the median values plus or minus one standard deviation, respectively $\mu+\sigma$ and $\mu-\sigma$. However, this variability is strongly reduced by specifying more the building category. It is generally assumed that overall variability is composed of random and epistemic components. Introducing more information on the structural behavior of the buildings can reduce 
epistemic uncertainty used for building fragility curves, as suggested by Spence et al. (2003), and confirmed by Perrault et al. (2013). For example (Table 1), when building material is introduced, the variability in wooden building response is highly reduced (e.g., $\sigma=0.49$ with AI). However the reduction is only slight for the other building categories. By adding information on height, we obtain variability values lower than 0.63 for HR-RC buildings for PGV, CAV or AI. For HR steel building category according to the Hazus definition (more than 8 floors), the variability of the response remain quite important (more than 1.0), as consequence of the wide range of number of floors. The year of construction, elevation or plan irregularities could be also introduced but this information is not available for all buildings tested herein. Even if $\mathrm{CAV}_{5}$ and $\mathrm{CAV}_{\text {std }}$ are defined with thresholds, they provide standard deviations very similar to those associated with CAV. PGA provides standard deviations greater than 0.75 , except for the wooden buildings category. For the six categories defined by concrete and steel materials, PGA provides a mean standard deviation equal to 0.99. PGV or AI will thus be used in order to reduce the variability in building response (see Electronic Supplement).

\section{INTENSITY MEASURES DEFINED BY SPECTRAL VALUES}

In this section, IMs are defined by the spectral values of acceleration, velocity and displacement, computed at a damping ratio of $5 \%$ and for the different frequency definitions. In order to take into account the frequency shift during seismic loading, Bommer et al. (2004) proposed to compute the spectral values between two periods: $T_{0}$ and $F . T_{0}$, where $T_{0}$ corresponds to the initial period and $\mathrm{F}$ is a fixed parameter to be determined in order to account for the frequency drop due to the non-linear response of civil engineering structures. The use of a frequency/period interval has already been proposed by Housner (1965) in the definition of the Response Spectrum Intensity, defined as the average spectral value in velocity between $0.1 \mathrm{~s}$ and $2.5 \mathrm{~s}$. In our case, we computed the mean values of spectral

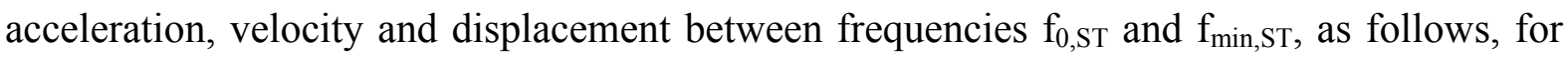
$\operatorname{Mean}(\mathrm{Sa})$ :

$$
\operatorname{Mean}\left[\operatorname{Sa}\left(\left[f_{\min , S T} ; f_{0, S T}\right] 5 \%\right)\right]=\frac{\int_{f_{\min , S T}}^{f_{0 S T}} S a(f, 5 \%) d f}{\left(\frac{f_{0, S T}-f_{\min , S T}}{d f}+1\right)}
$$


Table 1. Correlation between building response, represented by NRRD, and intensity measures: PGA, $\mathrm{PGV}, \mathrm{PGD}, \mathrm{CAV}, \mathrm{CAV}_{5}, \mathrm{CAV}_{\text {std }}$ and $\mathrm{AI}$. The values are the standard deviations associated with the first functional form (Equation 5) and with the second functional form (Equation 6). The numbers in brackets indicate the number of pieces of data available for each category of buildings. In each column, i.e. for each building class, the bold value indicates the smallest standard deviation. LR: lowrise buildings; MR: mid-rise buildings; HR: high-rise buildings.

\begin{tabular}{c|c|c|c|c|c|c|c|c|c|c|c|c}
\hline & Eq. & $\begin{array}{c}\text { All } \\
(772)\end{array}$ & $\begin{array}{c}\text { Steel } \\
(312)\end{array}$ & $\begin{array}{c}\text { Conc. } \\
(317)\end{array}$ & $\begin{array}{c}\text { Mason. } \\
(47)\end{array}$ & $\begin{array}{c}\text { Wood } \\
(13)\end{array}$ & $\begin{array}{c}\text { LR } \\
\text { Steel } \\
(86)\end{array}$ & $\begin{array}{c}\text { MR } \\
\text { Steel } \\
(81)\end{array}$ & $\begin{array}{c}\text { HR } \\
\text { Steel } \\
(145)\end{array}$ & $\begin{array}{c}\text { LR } \\
\text { Conc. } \\
(71)\end{array}$ & $\begin{array}{c}\text { MR } \\
\text { Conc. } \\
(116)\end{array}$ & $\begin{array}{c}\text { HR } \\
\text { Conc. } \\
(130)\end{array}$ \\
\hline \multirow{2}{*}{ PGA } & 5 & 1.101 & 1.160 & 0.957 & 1.241 & 0.698 & 0.763 & 0.998 & 1.375 & 1.023 & 0.947 & 0.900 \\
& 6 & 1.100 & 1.158 & 0.956 & 1.180 & 0.605 & 0.759 & 0.987 & 1.374 & 1.018 & 0.924 & 0.899 \\
\hline \multirow{2}{*}{ PGV } & 5 & 0.889 & 1.835 & 0.823 & 1.052 & 0.544 & 0.690 & 0.760 & 0.776 & 0.970 & 0.878 & 0.616 \\
& 6 & $\mathbf{0 . 8 8 8}$ & $\mathbf{0 . 8 2 6}$ & 0.823 & 1.046 & 0.521 & 0.690 & $\mathbf{0 . 7 0 1}$ & 0.767 & 0.970 & 0.872 & $\mathbf{0 . 6 1 5}$ \\
\hline \multirow{2}{*}{ PGD } & 5 & 0.945 & 0.846 & 0.931 & 1.213 & 0.695 & 0.872 & 0.809 & 0.657 & 1.023 & 0.936 & 0.802 \\
& 6 & 0.944 & 0.846 & 0.929 & 1.213 & 0.677 & 0.867 & 0.793 & $\mathbf{0 . 6 5 3}$ & 1.017 & 0.928 & 0.789 \\
\hline \multirow{2}{*}{$\mathrm{CAV}$} & 5 & 0.960 & 0.897 & 0.850 & 1.199 & 0.526 & 0.782 & 0.826 & 0.804 & 0.934 & 0.895 & 0.627 \\
& 6 & 0.960 & 0.897 & 0.850 & 1.186 & 0.518 & 0.776 & 0.813 & 0.795 & 0.932 & 0.889 & 0.627 \\
\hline \multirow{2}{*}{$\mathrm{CAV} V_{5}$} & 5 & 0.991 & 0.932 & 0.905 & 1.065 & 0.520 & 0.778 & 0.813 & 0.904 & 0.970 & 1.004 & 0.711 \\
& 6 & 0.969 & 0.907 & 0.862 & 1.044 & 0.503 & 0.720 & 0.809 & 0.889 & 0.956 & 0.916 & 0.679 \\
\hline \multirow{2}{*}{$\mathrm{CAV}_{\text {std }}$} & 5 & 0.955 & 0.852 & 0.875 & $\mathbf{1 . 0 0 9}$ & 0.547 & 0.744 & 0.874 & 0.775 & 1.023 & 0.971 & 0.691 \\
& 6 & 0.955 & 0.846 & 0.868 & $\mathbf{1 . 0 0 9}$ & 0.545 & 0.716 & 0.862 & 0.739 & 1.018 & 0.958 & 0.685 \\
\hline \multirow{2}{*}{$\mathrm{AI}$} & 5 & 0.924 & 0.890 & $\mathbf{0 . 8 0 3}$ & 1.131 & 0.491 & 0.666 & 0.797 & 0.913 & 0.921 & 0.826 & 0.632 \\
& 6 & 0.921 & 0.877 & $\mathbf{0 . 8 0 3}$ & 1.131 & $\mathbf{0 . 4 8 9}$ & $\mathbf{0 . 6 6 3}$ & 0.765 & 0.897 & $\mathbf{0 . 9 1 3}$ & $\mathbf{0 . 8 2 2}$ & 0.629 \\
\hline
\end{tabular}

where $d f$ is the discretisation frequency of $S a$, i.e. $M e a n(S a)$ is the arithmetic mean of $S a$ over the interval $\left[\mathrm{f}_{\mathrm{min}, \mathrm{ST}} ; \mathrm{f}_{0, \mathrm{ST}}\right]$.

Adding dynamic parameters, such as frequency and damping of the structures, allows further reduction of the relational variabilities between NRRD and IMs (Table 2 and Figure 6). The two functional forms (Equations 5 and 6) were tested and we report in Table 2 only standard deviations associated with the second functional form (Equation 6) that provide the smallest variabilities. For spectral displacements and spectral velocities, lower variabilities are obtained with frequency $\mathrm{f}=\mathrm{f}_{\mathrm{FFT}}$ (e.g., $\sigma=0.36$ for $\mathrm{HR} \mathrm{RC}$ buildings and $\sigma=0.52$ for $\mathrm{MR}$ steel buildings) and frequency $\mathrm{f}=\mathrm{f}_{0, \mathrm{ST}}$ (e.g., $\sigma=0.35$ for $\mathrm{HR} \mathrm{RC}$ buildings and $\sigma=0.51$ for MR steel buildings). However, these two frequencies provide higher variabilities when $\mathrm{Sa}(\mathrm{f}$, $5 \%$ ) is considered, even higher than the standard deviations given by the two empirical frequencies (Table 2). In fact, for spectral accelerations, the empirical frequencies provide reduced variabilities. For spectral velocities $\mathrm{Sv}$ and spectral displacements $\mathrm{Sd}, \mathrm{f}_{\mathrm{emp}}$, which is defined only from the number of floors, is associated with high values of variability. The 

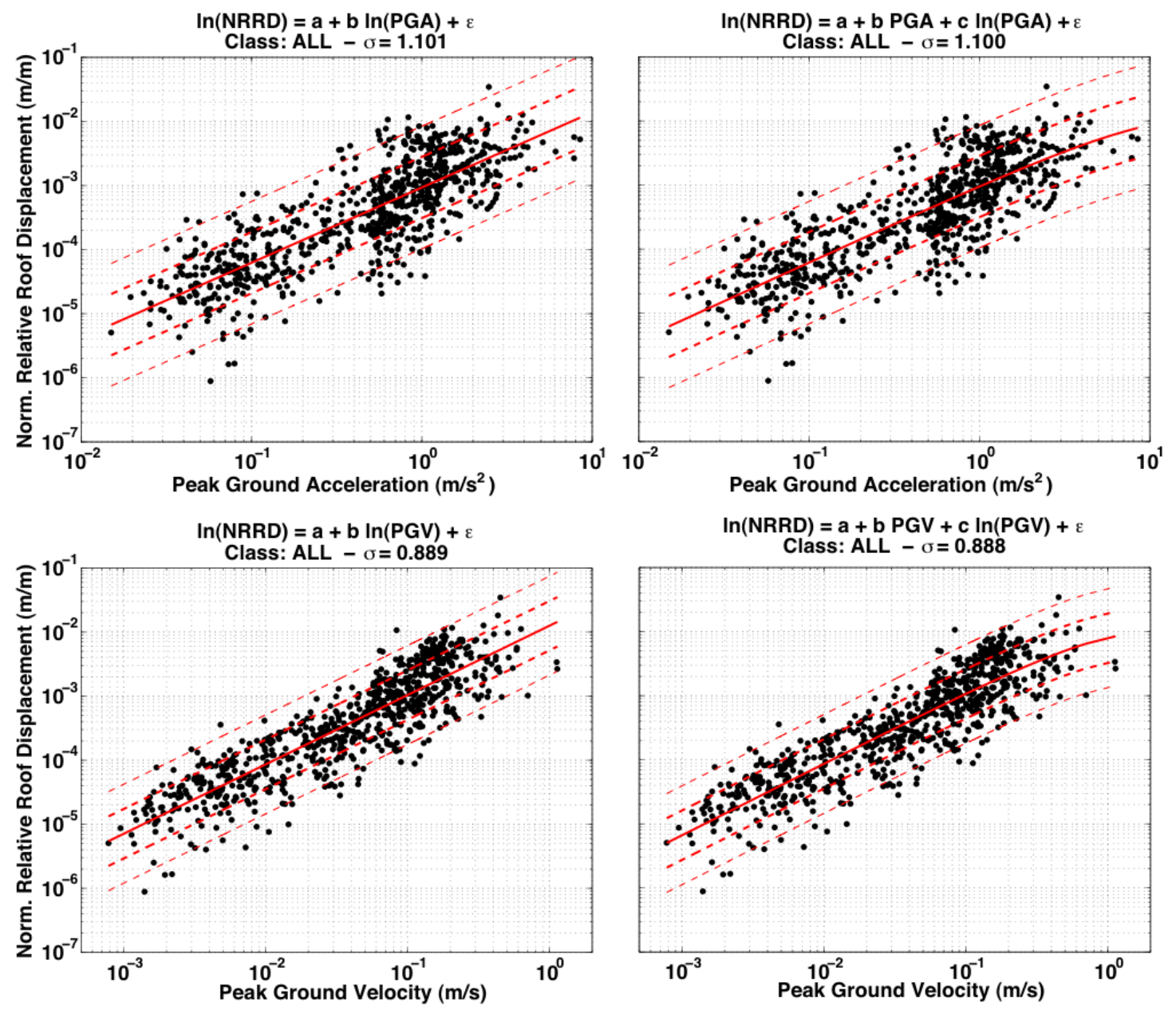

Figure 5. Comparison of the two functional forms (Equations 5 and 6 ) in order to represent NRRD as a function of intensity measures. The solid lines correspond to the median value, and the thick and thin dashed lines correspond to the median $+/-\sigma$ and $+/-2 \sigma$, respectively. Examples with PGA (first line) and PGV (second line). The standard deviations corresponding to each form are given in each title.

Eurocode 8 empirical frequency provides values that are as low as those obtained previously with PGV or AI.

Taking into account the frequency reduction during seismic loading over the interval $\left[f_{m i n, S T} ; f_{0, S T}\right]$ results in lower variability values (Figure 6), particularly for spectral accelerations and spectral velocities (e.g., $\sigma=0.59$ and $\sigma=0.52$ for low- and mid-rise steel buildings, respectively, and $\sigma=0.34$ for high-rise RC buildings). Variabilities of 0.35 provide a ratio between $\mu+\sigma$ and $\mu-\sigma$ equal to $\exp (2 \sigma) \approx 2$.

In conclusion, the introduction of dynamic parameters (frequencies and damping) of the structures for IMs and identification of building class improve the relationships between ground motion and building response. The Eurocode 8 empirical frequency provides higher 

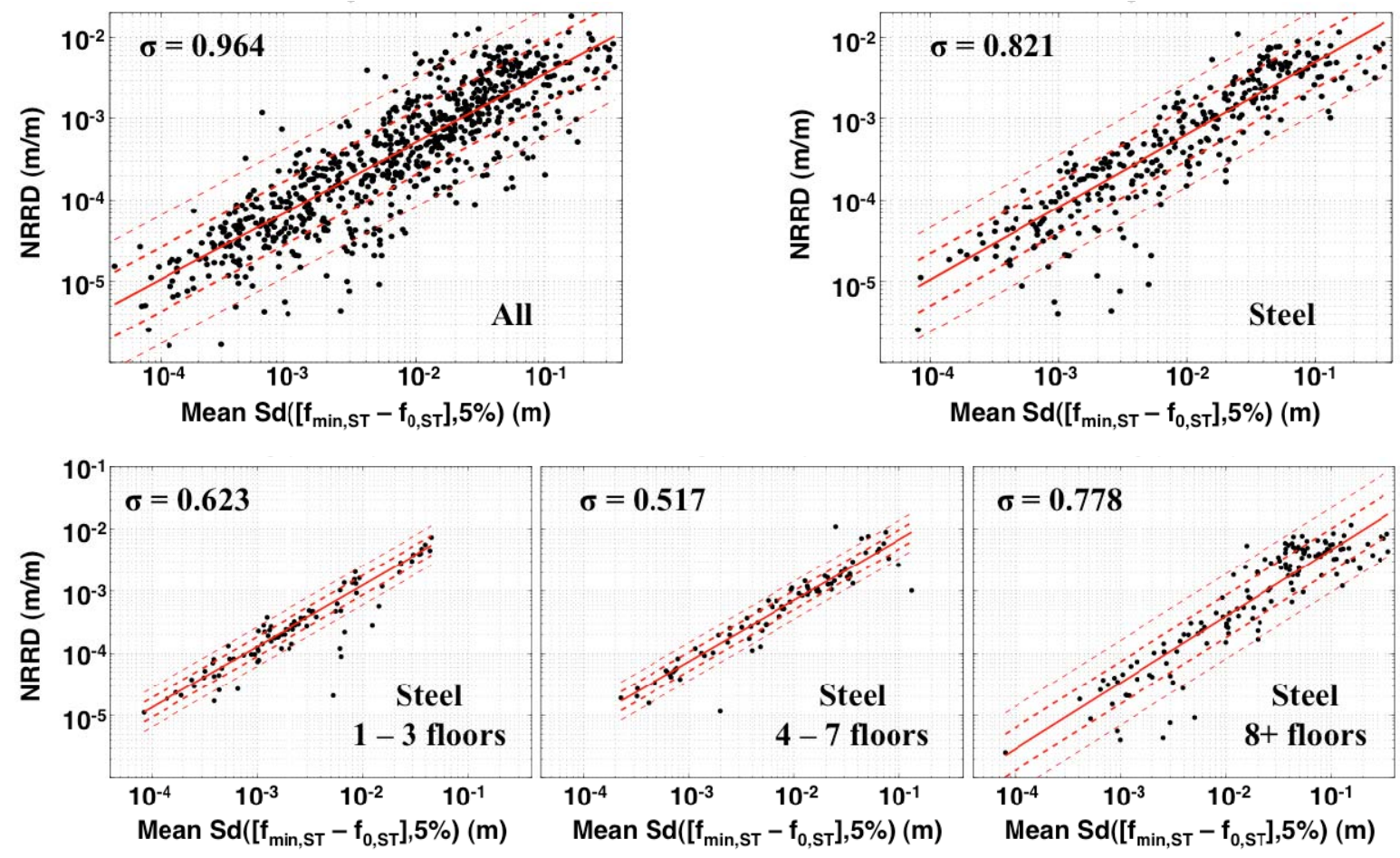

Figure 6. Normalized Relative Roof Displacement (NRRD) as a function of Mean(Sd) evaluated on the frequency interval $\left[\mathrm{f}_{\min , \mathrm{ST}} ; \mathrm{f}_{0, \mathrm{ST}}\right]$, for the following typologies: all buildings, steel buildings, and the three steel classes defined with the number of floors. $\sigma$ corresponds to the standard deviations provided by the second form (Equation 6) for each class of buildings. The thick and thin dashed red lines correspond to the median $+/-\sigma$ and $+/-2 \sigma$, respectively.

uncertainties, equal to those obtained with standard IMs. The NRRD, which is equivalent to the mean inter-storey drift, can thus be predicted from knowledge of the building material and the number of floors of the structures. Then, for a given ground motion scenario, the average $(+/-\sigma)$ value of the inter-storey drift can be computed for each building class. Additional parameters such as the year of construction, the quality of material, the plan and elevation irregularities could be introduced to reduce more the variability of the damage prediction. Herein, to be coherent with Hazus, we decided to consider only the material and the height of the building, the two parameters that were available for all buildings, ensuring thus a maximum usable data. 
Table 2. Correlation between the building response, represented by NRRD, and the intensity measures defined from spectral acceleration, velocities and displacements. The values are the standard deviations associated with the second functional form (Equation 6). The numbers in brackets indicate the number of pieces of data available for each class of buildings. In each column, i.e. for each building class, the bold value indicates the smallest standard deviation. LR: low-rise buildings; MR: mid-rise buildings; HR: high-rise buildings.

\begin{tabular}{|c|c|c|c|c|c|c|c|c|c|c|c|c|}
\hline & & $\begin{array}{c}\text { All } \\
(772)\end{array}$ & $\begin{array}{l}\text { Steel } \\
(312)\end{array}$ & $\begin{array}{l}\text { Conc. } \\
(317)\end{array}$ & $\begin{array}{c}\text { Mason. } \\
(47)\end{array}$ & $\begin{array}{c}\text { Wood } \\
(13)\end{array}$ & $\begin{array}{c}\text { LR } \\
\text { Steel } \\
(86) \\
\end{array}$ & $\begin{array}{c}\text { MR } \\
\text { Steel } \\
(81) \\
\end{array}$ & $\begin{array}{c}\text { HR } \\
\text { Steel } \\
(145) \\
\end{array}$ & $\begin{array}{c}\text { LR } \\
\text { Conc. } \\
(71)\end{array}$ & $\begin{array}{c}\text { MR } \\
\text { Conc. } \\
\text { (116) }\end{array}$ & $\begin{array}{c}\text { HR } \\
\text { Conc. } \\
(130) \\
\end{array}$ \\
\hline \multirow{3}{*}{$\mathrm{f}_{\mathrm{FFT}}$} & $\mathrm{Sa}$ & 1.334 & 1.243 & 1.193 & 1.243 & 0.458 & 0.775 & 0.981 & 1.199 & 1.076 & 1.233 & 0.994 \\
\hline & $\mathrm{Sv}$ & 0.957 & 0.777 & 0.847 & 1.128 & 0.671 & 0.597 & 0.648 & 0.807 & 1.059 & 0.906 & 0.513 \\
\hline & $\mathrm{Sd}$ & 0.971 & 0.827 & 0.895 & 1.221 & 0.810 & 0.622 & 0.519 & 0.792 & 1.139 & 0.836 & 0.361 \\
\hline \multirow{3}{*}{$\mathrm{f}_{0, \mathrm{ST}}$} & $\mathrm{Sa}$ & 1.285 & 1.178 & 1.154 & 1.188 & 0.473 & 0.756 & 0.930 & 1.124 & 1.052 & 1.186 & 0.942 \\
\hline & $\mathrm{Sv}$ & 0.951 & 0.779 & 0.845 & 1.153 & 0.714 & 0.604 & 0.618 & 0.835 & 1.061 & 0.912 & 0.470 \\
\hline & $\mathrm{Sd}$ & 0.980 & 0.837 & 0.909 & 1.243 & 0.856 & 0.647 & 0.508 & 0.798 & 1.131 & 0.876 & 0.348 \\
\hline \multirow{3}{*}{$\mathrm{f}_{\mathrm{min}, \mathrm{ST}}$} & $\mathrm{Sa}$ & 1.351 & 0.815 & 1.233 & 1.217 & 0.469 & 0.803 & 1.043 & 1.178 & 1.093 & 1.256 & 1.056 \\
\hline & $\mathrm{Sv}$ & 0.952 & 0.792 & $\mathbf{0 . 8 3 7}$ & 1.109 & 0.675 & 0.607 & 0.682 & 0.821 & 1.020 & 0.881 & 0.546 \\
\hline & $\mathrm{Sd}$ & 0.950 & 1.247 & 0.867 & 1.221 & 0.812 & 0.622 & 0.538 & 0.773 & 1.085 & 0.800 & 0.385 \\
\hline \multirow{3}{*}{$\begin{array}{c}{\left[\mathrm{f}_{\min , \mathrm{ST}} ;\right.} \\
\left.\mathrm{f}_{0, \mathrm{ST}}\right] \\
\text { Mean: }\end{array}$} & $\mathrm{Sa}$ & 1.316 & 1.210 & 1.188 & 1.192 & 0.460 & 0.777 & 0.986 & 1.141 & 1.068 & 1.227 & 0.989 \\
\hline & $\mathrm{Sv}$ & 0.949 & 0.773 & 0.842 & 1.119 & 0.683 & 0.593 & 0.646 & 0.808 & 1.045 & 0.900 & 0.492 \\
\hline & $\mathrm{Sd}$ & 0.964 & 0.821 & 0.887 & 1.224 & 0.824 & 0.623 & 0.517 & 0.778 & 1.113 & 0.836 & 0.341 \\
\hline \multirow{3}{*}{$\begin{array}{l}f_{\text {emp }}= \\
10 / N\end{array}$} & $\mathrm{Sa}$ & 1.188 & 1.101 & 1.043 & 1.446 & 0.778 & 0.759 & 0.734 & 0.811 & 1.126 & 1.012 & 0.666 \\
\hline & Sv & 1.085 & 0.865 & 1.205 & 1.437 & 0.859 & 0.769 & 0.812 & 0.726 & 1.549 & 0.954 & 0.561 \\
\hline & $\mathrm{Sd}$ & 1.263 & 1.058 & 1.407 & 1.613 & 0.744 & 0.713 & 0.800 & 0.783 & 1.637 & 0.922 & 0.652 \\
\hline \multirow{3}{*}{$\mathrm{f}_{\mathrm{emp}, \mathrm{EC} 8}$} & $\mathrm{Sa}$ & 1.134 & 0.950 & 0.924 & 1.285 & 0.599 & 0.752 & 0.713 & 0.657 & 0.880 & 0.937 & 0.679 \\
\hline & $\mathrm{Sv}$ & 0.879 & 0.761 & 0.845 & 1.202 & 0.611 & 0.625 & 0.711 & 0.702 & 0.993 & 0.879 & 0.609 \\
\hline & $\mathrm{Sd}$ & 0.941 & 0.792 & 0.989 & 1.156 & 0.577 & 0.616 & 0.683 & 0.703 & 1.109 & 0.843 & 0.684 \\
\hline
\end{tabular}

\section{BUILDING DAMAGE PREDICTION EQUATION}

According to the IMs used to represent ground motion, the prediction of building response can be computed empirically considering NRRD, i.e. by predicting a certain level of damage. Hancock et al. (2008) proposed a functional form in which DM is related to moment magnitude, Joyner-Boore distance and parameters dependent on fault characteristics. However, these parameters are not available immediately after an earthquake. We therefore decided to develop a functional form providing NRRD as a function of IMs, consistent with the functional model proposed by Luco (2002) and Hancock et al. (2008) for damage prediction. By combining several IMs we aim to reduce variability even further, by predicting the building response according to the formula:

$$
g(D M)=a+f_{1}\left(I M_{1}\right)+\mathrm{K}+f_{i}\left(I M_{i}\right)+\mathrm{K}+f_{n}\left(I M_{n}\right)
$$


where $D M$ is a damage measurement and $I M_{i}$ intensity measure. The $g, f_{l}, \ldots, f_{n}$ functions are the functions that represent the damage parameter and the associated IMs.

The main objective of this paper is to define empirical models for damage prediction, based on IMs. They do not require lengthy processing and within the framework of contributing to earthquake warnings, we must account for efficient IMs according to Luco (2002) definition, such as PGA or Sd. In view of the above, we chose to represent ground motion by the following IMs: PGA, CAV, Sd and the mean value of Sv computed on a frequency interval. These IMs can be obtained directly from field data and used for buildingspecific damage prediction, or predicted using ground motion prediction equations (GMPEs) that can be integrated into warning systems. The first three parameters are equivalent to acceleration, velocity and displacement respectively, and this combination covers a large frequency band of ground motion. According to Wald et al. (1999), these IMs are complementary, although these authors deal with the three peaks (i.e. PGA, PGV and PGD) rather than PGA, CAV and Sd. The CAV is selected because it is computed directly on the accelerogram, without integration and then faster for warning systems. The last IM used in the functional form is $\mathrm{Sv}$ averaged over the interval $\left[\mathrm{f}_{\min , \mathrm{bldg}} ; \mathrm{f}_{0, \mathrm{bldg}}\right.$ ], in order to take into account the building frequency decay during seismic loading and providing the smallest variability of building responses. For each $\mathrm{IM}$, the form $f_{i}=a+b \ln (I M)+c I M+\varepsilon$ provides lower uncertainties in the prediction of $\ln (\mathrm{NRRD})$, except for CAV, for which the first form (i.e. $f_{i}=a+b \ln (I M)+\varepsilon$ ) provides the same uncertainties (see Electronic Supplement). Finally, the following functional form is considered:

$$
\begin{aligned}
\ln (N R R D)= & a+b P G A+c \ln (P G A)+d \ln (C A V)+e S d\left(f_{\text {bldg }}, 5 \%\right) \\
& +f \ln \left(S d\left(f_{\text {bldg }}, 5 \%\right)\right)+g \operatorname{Mean}\left[S v\left(\left[f_{\text {min }, \text { bldg }}-f_{0, b l d g}\right], 5 \%\right)\right] \\
& +h \ln \left(\operatorname{Mean}\left[\operatorname{Sv}\left(\left[f_{\text {min,bldg }}-f_{0, b l d g}\right], 5 \%\right)\right]\right)+\varepsilon
\end{aligned}
$$

where $\mathrm{f}_{\text {bldg }}$ is the frequency of the building, $\mathrm{f}_{0, \mathrm{bldg}}$ corresponds to the pre-seismic frequency and $\mathrm{f}_{\text {min,bldg }}$ is the minimal co-seismic frequency. $\varepsilon$ is the term corresponding to the residuals, i.e. equivalent to the variability in building response. Coefficients $a, b, c, d, e, f, g$ and $h$ are assessed from the database of recordings from Californian buildings, by performing a 50,000iteration simulated annealing process. Simulated annealing is a Monte Carlo method developed to find the global minimum of challenging functions having many local minima (Kirkpatrick, 1984; Chen et al., 1991). This method requires a global minimum of a scalar 
function called cost function in order to converge to a local minimum. Optimization consists in finding the optimal state that minimizes the cost function describing in our case the difference between the NRRD observed and calculated, i.e. aimed at minimizing the difference between the left and right parts of Equation 9. In this study, the cost function is the standard deviation of the residuals (Res) between observed and calculated NRRD, i.e.:

$$
\text { Cost }=\sqrt{\mathrm{E}\left[\operatorname{Res}^{2}\right]-\mathrm{E}[\operatorname{Res}]^{2}}
$$

where $\mathbf{E}$ is the expectation operator and Res $=\ln \left(\mathrm{NRRD}_{\mathrm{obs}}\right)-\ln \left(\mathrm{NRRD}_{\mathrm{mod}}\right)$.

We chose to use a variant of simulated annealing, the Very fast simulated Annealing (Ingber, 1989). This method generates a new state from a reference state, associated with an initial cost. The first step is to validate the inversion process. The 8 coefficients are initially set to randomly determined values $a_{0}, b_{0}, c_{0}, d_{0}, e_{0}, f_{0}, g_{0}$ and $h_{0}$. A standard deviation term $\sigma_{0}$ is also introduced whereby the residuals $\varepsilon$ of Equation 9 are described by a normal distribution $N\left(0, \sigma_{0}{ }^{2}\right)$. Using the ground motion parameters (IMs) of Equation 9 (PGA, CAV, $\mathrm{Sd}$ and Mean(Sv)) and considering $a_{0}, b_{0}, c_{0}, d_{0}, e_{0}, f_{0}, g_{0}, h_{0}$ and $\sigma_{0}$, synthetic values of $\ln (N R R D)$ are computed by applying Equation 9. Once the run finished, the synthetics NRRD and the four observed IMs are used for assessing the coefficients $a$ to $h$ and $\sigma$ using the simulated annealing and compared to the initial values $a_{0}, b_{0}, c_{0}, d_{0}, e_{0}, f_{0}, g_{0}, h_{0}$ and $\sigma_{0}$ (Figure 7). For a slight variability of the residuals $\varepsilon\left(\sigma_{0}\right)$, the coefficients are well assessed, whereas for higher $\sigma_{0}$ values, coefficient determination is less accurate (Figure 8). However, as shown in Figure 8i, the inversion of the variability of residuals $\left(\sigma_{0}\right)$ minimizes errors of the residuals $(3.6 \%)$ whatever the variability of the original residuals. These two tests show that even if the accuracy of the inversion of coefficients $a$ - $h$ depends on the original variability of the data, the observed variability does not introduce trade-off in the inversion of coefficients.

In Equation 9, different frequencies are mentioned. Several definitions of frequencies were assessed in the previous part, with or without the records. Two cases are considered here:

Case 1: the real frequencies of the buildings, such as:

$\mathrm{f}_{\text {bldg }}=\mathrm{f}_{\mathrm{FFT}}$ and $\left[\mathrm{f}_{\text {min,bldg }} ; \mathrm{f}_{0, \mathrm{bldg}}\right]=\left[\mathrm{f}_{\mathrm{min}, \mathrm{ST}} ; \mathrm{f}_{0, \mathrm{ST}}\right]$;

Case 2: the empirical frequencies, such as: 

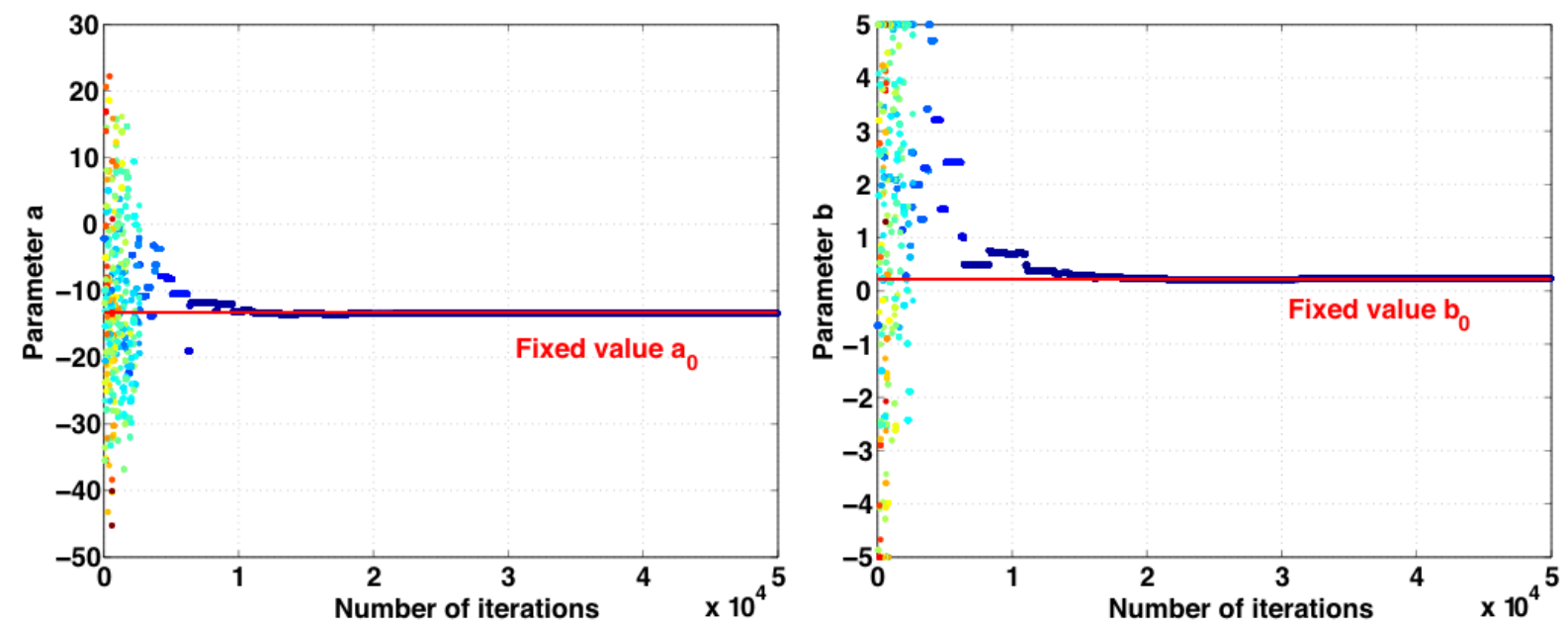

Figure 7. Example of the simulated annealing processing, to test the inversion of coefficients $a$ and $b$ for a given value of variability of residuals $\varepsilon$. The values $a_{0}$ and $b_{0}$ are initially set (red line) and 50,000 iterations of the simulated annealing process are used for converging. Red dots correspond to high values of the cost function and the more the dots are blue, the more the cost function is low.

$\mathrm{f}_{\text {bldg }}=\mathrm{f}_{\text {emp }, \mathrm{EC} 8}$ and $\left[\mathrm{f}_{\mathrm{min}, \mathrm{bldg}} ; \mathrm{f}_{0, \mathrm{bldg}}\right]=\left[0.25 . \mathrm{f}_{\mathrm{emp}, \mathrm{EC} 8} ; 2 . \mathrm{f}_{\mathrm{emp}, \mathrm{EC} 8}\right]$.

The advantage of the first case is to have lower variabilities by combining the best IMs while the second case requires only an empirical estimate of building frequency. We compared the empirical estimates ( $\left.f_{\text {emp,ECs }}\right)$ to the FFT and S-transform estimates of real frequencies $\left(f_{F F T}, f_{\text {min,bldg }}\right.$ and $f_{0, b l d g}$ ), showing variabilities related to the degradation of the frequency during the shaking and to the variability of the real frequencies into a class of buildings. According to our results, we introduced a factor of 0.25 to account for the potential frequency degradation during seismic loading and a factor of 2 to account for variability of empirical frequency within a building category.

For each building class, a series of coefficients is provided (see Electronic Supplement), and associated with variability $\sigma$, as shown in Table 3. As expected, the functional form given in Equation 9 allows a reduction of variabilities for each class. For example, for midrise $\mathrm{RC}$ buildings with a single IM, the lowest variability was 0.84 , which was obtained with $\mathrm{Sd}\left(\mathrm{f}_{\mathrm{FFT}}, 5 \%\right)$, whereas the enhanced functional form provides a variability of 0.69 and 0.76 for cases 1 and 2. As expected, the introduction of real rather than empirical frequencies gives the best standard deviations, e.g. for the high-rise concrete building class (see Figure 9). However, for the simulation of earthquakes losses at a global scale, it is difficult to obtain experimental frequencies. The use of empirical frequencies is a relevant solution that does not require building recordings. Moreover, the variabilities associated with empirical 

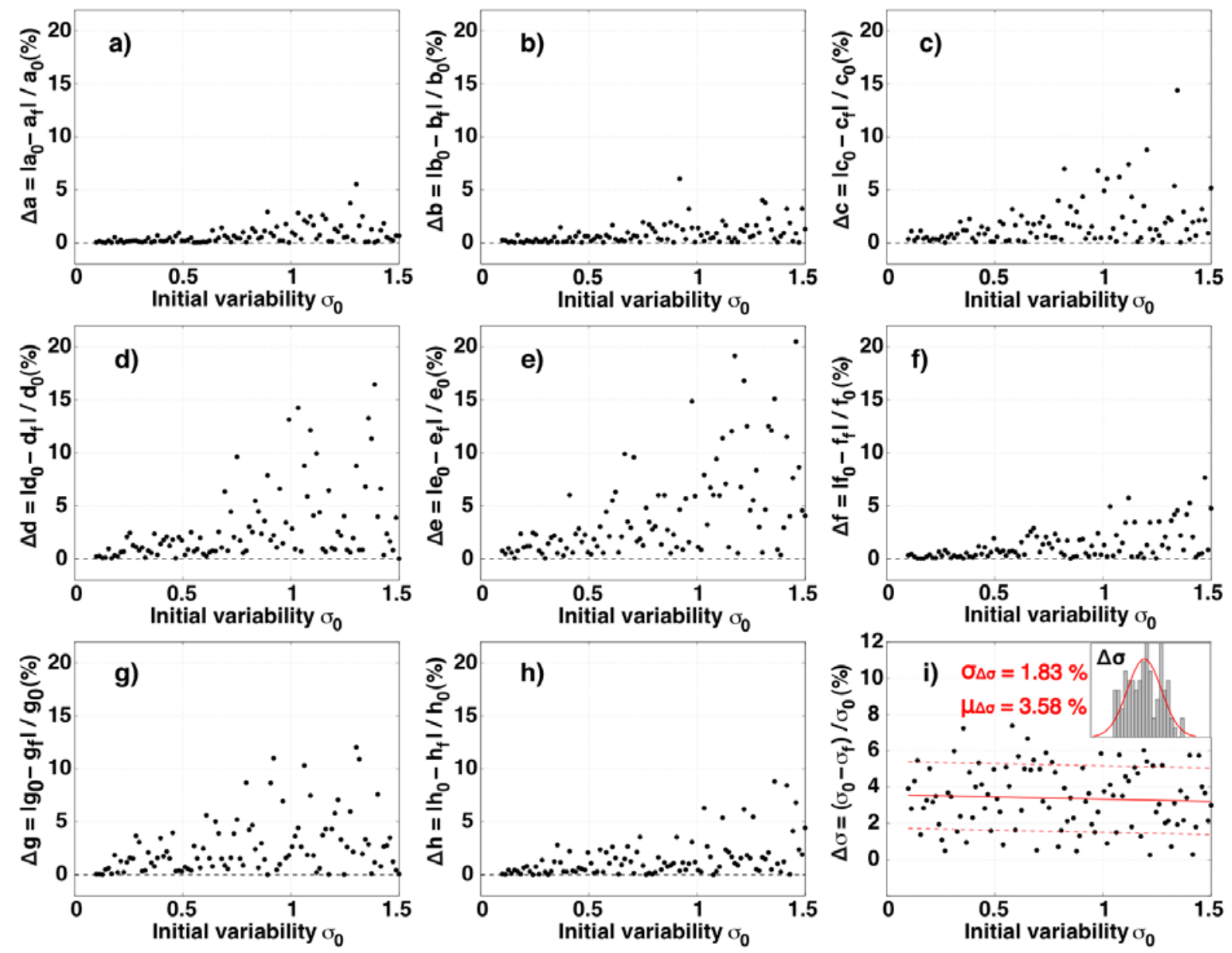

Figure 8. Accuracy of the simulated annealing process for the inversion of coefficients $a$ to $h$ of Equation 9 (label a to $h$ in the subplots), following the initial variability $\sigma_{0}$ introduced to represent the distribution of the normally distributed residuals $\varepsilon$ (i). The histogram corresponds to the distribution of the $\Delta \sigma$ values (differences between initial and final value in $\%)(\sigma$ of Equation 9$)$.

frequencies present low values, which can be lower than with real frequencies (e.g. for all buildings in the masonry building class and for high-rise steel buildings).

\section{CONCLUSION}

On the basis of the CSMIP database of earthquake recordings from Californian buildings, the correlation between building response, described by the normalized relative roof displacement (NRRD), and intensity measures IMs, such as PGA, PGV, CAV and Sd, was studied. It appears that classifying the buildings by typology may reduce the epistemic variability of building response. Moreover, IMs that use the dynamic parameters of buildings provide the lowest standard deviations (e.g., $\mathrm{Sd}\left(\mathrm{f}_{\mathrm{FFT}}\right)$ provides a mean standard deviation $\sigma_{\text {mean }}=0.71$ for the six building classes defined according to construction material and 
Table 3. Variabilities associated with IMs PGA, CAV, $\mathrm{Sd}\left(\mathrm{f}_{\mathrm{bldg}}, 5 \%\right)$ and $\left.\operatorname{Mean}\left(\mathrm{Sv}\left[\mathrm{f}_{\text {min,bldg }} ; \mathrm{f}_{0, \mathrm{bldg}}\right], 5 \%\right)\right)$ when used alone (Tables 1 and 2) to describe ground motion and when combined according to Equation 9 (two last columns), using real or empirical frequencies. Variabilities are also given when IMs are added one by one in Equation 9. The sigma values of the fifth column ( $\mathrm{Sd}$ ) were obtained with $\mathrm{f}_{\text {bldg }}=f_{\mathrm{FFT}}$, and those from the sixth column (Mean $\left.(\mathrm{Sv})\right)$ with $\left[\mathrm{f}_{\text {min,bldg }} ; \mathrm{f}_{0, \mathrm{bldg}}\right]=\left[\mathrm{f}_{\text {min,ST }} ; \mathrm{f}_{0, \mathrm{ST}}\right]$. LR: low-rise buildings; MR: mid-rise buildings; HR: high-rise buildings.

\begin{tabular}{|c|c|c|c|c|c|c|c|c|c|c|}
\hline & & \multicolumn{3}{|c|}{ Previous part results } & \multicolumn{3}{c|}{$\begin{array}{c}\text { Equation 9 results } \\
\text { by using only }\end{array}$} & \multicolumn{2}{c|}{ Equation 9 results } \\
\hline & & PGA & CAV & Sd & $\begin{array}{c}\text { Mean } \\
\text { Sv }\end{array}$ & PGA & $\begin{array}{c}\text { PGA \& } \\
\text { CAV }\end{array}$ & $\begin{array}{c}\text { PGA \& } \\
\text { CAV \& } \\
\text { Sd(fFT }\end{array}$ & $\begin{array}{c}\text { Real } \\
\text { frequencies }\end{array}$ & $\begin{array}{c}\text { Empirical } \\
\text { frequencies }\end{array}$ \\
\hline 1 & All & 1.10 & 0.96 & 0.97 & 0.95 & 1.10 & 0.93 & 0.87 & 0.86 & 0.83 \\
\hline 2 & Steel & 1.16 & 0.90 & 0.83 & 0.77 & 1.16 & 0.88 & 0.77 & 0.75 & 0.70 \\
\hline 3 & Concrete & 0.96 & 0.85 & 0.90 & 0.84 & 0.96 & 0.80 & 0.76 & 0.76 & 0.78 \\
\hline 4 & Masonry & 1.18 & 1.19 & 1.22 & 1.11 & 1.18 & 1.08 & 1.07 & 1.03 & 0.86 \\
\hline 5 & Wood & 0.61 & 0.51 & 0.81 & 0.68 & 0.61 & 0.50 & 0.49 & 0.31 & 0.39 \\
\hline 6 & LR Steel & 0.76 & 0.78 & 0.62 & 0.59 & 0.76 & 0.68 & 0.57 & 0.56 & 0.54 \\
\hline 7 & MR Steel & 0.99 & 0.81 & 0.52 & 0.65 & 0.99 & 0.78 & 0.52 & 0.50 & 0.64 \\
\hline 8 & HR Steel & 1.37 & 0.80 & 0.79 & 0.81 & 1.37 & 0.79 & 0.72 & 0.70 & 0.61 \\
\hline 9 & LR Concrete & 1.02 & 0.93 & 1.14 & 1.05 & 1.02 & 0.89 & 0.88 & 0.88 & 0.87 \\
\hline 10 & MR Concrete & 0.92 & 0.89 & 0.84 & 0.90 & 0.92 & 0.80 & 0.75 & 0.69 & 0.76 \\
\hline 11 & HR Concrete & 0.90 & 0.63 & 0.36 & 0.49 & 0.90 & 0.61 & 0.35 & 0.35 & 0.54 \\
\hline & $\begin{array}{c}\sigma_{\text {mean }} \text { : mean on } \\
\text { classes 6 to 11 }\end{array}$ & 0.99 & 0.81 & 0.71 & 0.75 & 0.99 & 0.76 & 0.63 & 0.61 & 0.66 \\
\hline
\end{tabular}

number of floors. See Table 3). The combination of four IMs, i.e. PGA, CAV, Sd and $\mathrm{Mean}(\mathrm{Sv})$ for a predictive equation of the expected response derived from experimental data provides lower standard deviations in the building response $\left(\sigma_{\text {mean }}=0.61\right.$ when real frequencies are used). Since structural drift is considered, this equation can be considered as the first step towards the building damage prediction equation (BDPE), considering NRRD as damage criteria according to Hazus methodology.

After testing several solutions, we find that the functional form using several IMs (Equation 9) gives the smallest variability of results, especially when the residual distribution is analyzed (Figure 9). This functional form and its coefficients assessed by simulated annealing are only compatible with the data used in this paper. These data are for California buildings, mainly in steel and reinforced concrete. The data correspond to earthquakes of magnitude between 3.5 and 7.0, and epicentral distances between 2 and $400 \mathrm{~km}$. Rather than speaking of earthquake parameters, we believe that it is preferable to set the domain of validity of the empirical model for drift between $2.10^{-6}$ and $2.10^{-2} \mathrm{~m} / \mathrm{m}$. This model must be 

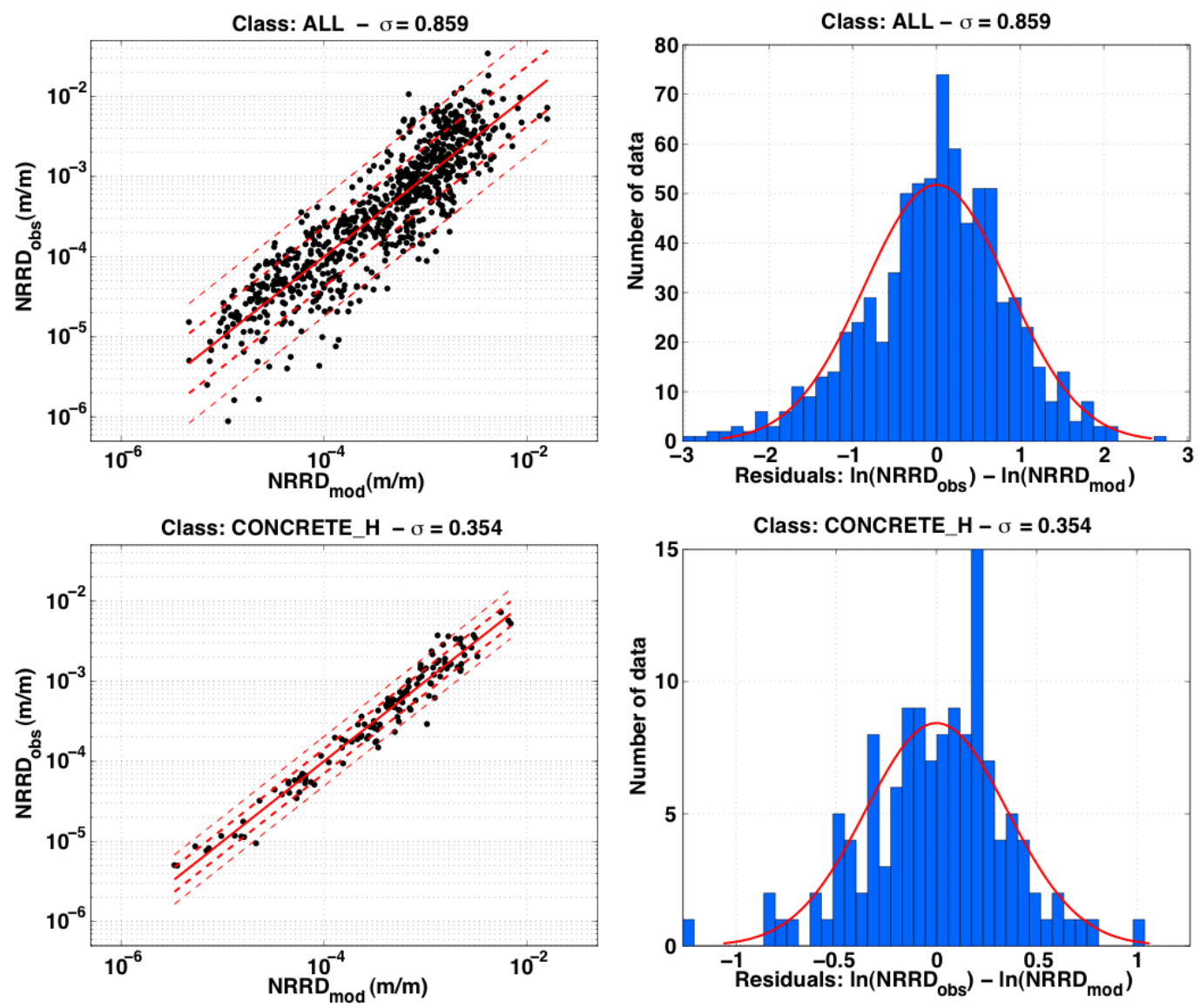

Figure 9. Left: comparison of observed NRRD as a function of synthetic NRRD, computed using Equation 9 and introducing real frequencies. Right: associated residuals, described by a normal distribution. Example for all buildings (first line) and high-rise concrete buildings (second line). Standard deviations are given in the titles. The thick and thin dashed red lines correspond to the median $+/-\sigma$ and $+/-2 \sigma$, respectively.

confirmed, especially by testing it on other types of construction. It can also be refined by reducing the uncertainties through the introduction of additional information for the building classification (e.g. date of construction, design, etc ...). Moreover, building-specific analysis (i.e., considering one building and several earthquakes) could improve information on the uncertainties related to the IM versus drift relationships, the number of these data being by now to small for carrying out an extensive analysis. When associated with empirical frequencies, it provides good estimates of NRRD $\left(\sigma_{\text {mean }}=0.66\right.$ when empirical frequencies are used), which can be used in an earthquake early warning system, by comparing estimated NRRD with reference values for inter-storey drift defined for different damage levels (e.g. FEMA, 1999). Since empirical frequencies depend on the building height, this information can be easily filled from field survey, national census or remote sensing. Moreover, the 
damage prediction equation can also be used to build fragility curves for the associated building classes (Perrault, 2013).

\section{AKNOWLEDGMENT}

This work was supported by the ANR (National Research Agency) as part of its RiskNat program (URBASIS project, no. ANR-09-RISK-009). Data were provided by the California Strong Motion Instrumentation Program (CSMIP), through the CSMIP web data access (http://strongmotioncenter.org/).

\section{REFERENCES}

Ambrasey, N.N., Douglas, J., Sarma, S.K. and Smit, P.M., 2005. Equations for the estimation of strong ground motions from shallow crustal earthquakes using data from Europe and the Middle East: horizontal peak ground acceleration and spectral acceleration, Bulletin of Earthquake Engineering, 3, 1-53.

Arias, A., 1970. A measure of earthquake intensity. Seismic design for Nuclear Power Plants, MIT Press : Cambridge, MA, pp. 438-483.

Borzi, B., Calvi, G.M., Elnashai, A.S., Faccioli, E. and Bommer, J.J., 2001. Inelastic spectra for displacement-based seismic design. Soil Dynamics and Earthquake Engineering, 21(1), 47-61.

Bommer, J. J., Magenes, G., Hancock, J., and Penazzo, P., 2004. The influence of strong-motion duration on the seismic response of masonry structures, Bulletin of Earthquake Engineering, 2(1), 1-26.

Calvi, G. M., Pinho, R., Magenes, G., Bommer, J. J., Restrepo-Vélez, L. F., and Crowley, H., 2006. Development of seismic vulnerability assessment methodologies over the past 30 years, Indian Society Journal of Earthquake Technology, 43(3), 75-104.

CEN, 2005. Eurocode 8 - Design of Structures for earthquake resistance - Part 1 : General rules, seismic actions and rules for buildings. European Standard EN 1998-1, Comité Européen de Normalisation, Brussels, Belgium.

Chen, G. S., Bruno, R. J., and Salama, M. 1991. Optimal placement of active/passive members in truss structures using simulated annealing. AIAA journal, 29(8), 1327-1334.

Clinton, J., Bradford, S. C., Heaton, T. H., and Favela, J., 2006. The observed wander of the natural frequencies in a structure. Bulletin of the Seismological Society of America, 96(1), 237-257.

Clough, R. W., and Penzien, J., 1993. Dynamics of structures, vol. 2. McGraw-Hill New York.

Dunand, F., Ait Meziane, Y., Guéguen, P., Chatelain, J.-L., Guillier, B., Ben Salem, R., Hadid, M., Hellel, M., Kiboua, A., Laouami, N., Machane, D., Mezouer, N., Nour, A., Oubaiche, E.H., and Remas, A., 2004. Utilisation du bruit de fond pour l'analyse des dommages des bâtiments de Boumerdes suite au séisme du 21 mai 2003. Mém Serv. Géol. Alg., 12, 177-191.

EPRI, 1988. A criterion for determining exceedance of the operating basis earthquake, EPRI Report $N P$-5930, Electrical Power Research Institute, Palo Alto, CA.

EPRI, 1991. Standardization of the Cumulative Absolute Velocity. EPRI Report TR-100082, Electrical Power Research Institute, Palo Alto, CA.

Earthquake Engineering Research Institute (EERI), 1994. Expected Seismic Performance of Buildings. (Oakland, CA: EERI).

FEMA, 1999. HAZUS Earthquake loss estimation methodology. Federal Emergency Management Agency, Washington, D.C. 
Hancock, J., Bommer, J. J., and Stafford, P. J., 2008. Numbers of scaled and matched accelerograms required for inelastic dynamic analyses, Earthquake Engineering and Structural Dynamics, 37(14), 1585-1607.

Housner, G. W., 1965. Intensity of ground shaking near the causative fault, Proceedings of the third World Conference on Earthquake Engineering, 1, p. 81-94, Auckland, New Zealand.

Ingber, L., 1989. Very fast simulated re-annealing. Mathematical and computer modelling, 12(8), 967-973.

Kirkpatrick, S., 1984. Optimization by simulated annealing: Quantitative studies. Journal of statistical physics, 34(5-6), 975-986.

Krishnan, S., Casarotti, E., Goltz, J., Ji, C., Komatitsch, D., Mourhatch, R., Muto, M., Shaw, J. H., Tape, C., and Tromp, J., 2012. Rapid estimation of damage to tall buildings using near real-time earthquake and archived structural simulations, Bulletin of the Seismological Society of America, 102(6), 2646-2666.

Lesueur, C., Cara, M., Scotti, O., Schlupp, A., and Sira, C., 2013. Linking ground motion measurements and macroseismic observations in France: a case study based on accelerometric and macroseismic databases. Journal of Seismology, 17(2), 313-333.

Luco, N., 2002. Probabilistic seismic demand analysis, SMRF connection fractures, and near-source effects. PhD dissertation, Department of Civil and Environmental Engineering, Stanford University.

McGuire, R. K., 2004. Seismic hazard and risk analysis. Earthquake Engineering Research Institute.

Michel, C., and Guéguen, P., 2010. Time-frequency analysis of small frequency variations in civil engineering structures under weak and strong motions using a reassignment method, Structural Health Monitoring, 9(2), 159-171.

Michel, C., Guéguen, P., and Causse, M., 2012. Seismic vulnerability assessment to slight damage based on experimental modal parameters, Earthquake Engineering and Structural Dynamics, 41(1), 81-98.

Michel, C., Zapico, B., Lestuzzi, P., Molina, F. J., and Weber, F., 2011. Quantification of fundamental frequency drop for unreinforced masonry buildings from dynamic tests, Earthquake Engineering and Structural Dynamics, 40(11), 1283-1296.

Milutinovic, Z. V., and Trendafiloski, G. S., 2003. Risk-UE: an advanced approach to earthquake risk scenarios with applications to different European towns, WP4: Vulnerability of current buildings. European Project.

NBCC, 2005. National Building Code of Canada 2005, National Research Council of Canada, Ottawa, Ontario.

Perrault, M., 2013. Évaluation de la vulnérabilité sismique de bâtiments à partir de mesures in situ. $\mathrm{PhD}$ dissertation, Grenoble University, France. In French.

Perrault, M., Guéguen, P., Aldea, A., and Demetriu, S., 2013. Using experimental data to reduce the single-building sigma of fragility curves: case study of the BRD Tower (Bucharest - Romania), Earthquake Engineering and Engineering Vibration, 12(4): 643-658.

Spence, R. J. S., Bommer, J. J., Del Re, D., Bird, J., Aydinog lu, N., and Tabuchi, S., 2003. Comparing loss estimation with observed damage: a study of the 1999 Kocaeli earthquake in Turkey, Bulletin of Earthquake Engineering, 1(1), 83-113.

Stockwell, R. G., Mansinha, L., and Lowe, R. P., 1996. Localization of the complex spectrum: the S transform. IEEE Transactions on Signal Processing, 44(4), 998-1001.

Todorovska, M. I., and Trifunac, M. D., 2007. Earthquake damage detection in the Imperial County Services Building I: The data and time-frequency analysis. Soil Dynamics and Earthquake Engineering, 27(6), 564-576.

Wald, D., Lin, K. W., Porter, K., and Turner, L., 2008. ShakeCast: Automating and improving the use of ShakeMap for post-earthquake decision-making and response, Earthquake Spectra, 24(2), 
$533-553$.

Wald, D. J., Quitoriano, V., Heaton, T. H., and Kanamori, H., 1999. Relationships between peak ground acceleration, peak ground velocity, and modified Mercalli intensity in California, Earthquake Spectra, 15, 557-564.

Worden, C. B., Wald, D. J., Allen T. I., Lin, K., Garcia, D., and Cua, G., 2010. A revised ground motion and intensity interpolation scheme for shakemap, Bulletin of the Seismological Society of America, 100(6), 3083-3096.

Wu, Y. M., Hsiao, N. C., Teng, T. L., and Shin, T. C., 2002. Near real-time seismic damage assessment of the rapid reporting system. Terrestrial Atmospheric and Oceanic Sciences, 13(3), 313-324.

Wu, Y. M., Teng, T. L., Shin, T. C., and Hsiao, N. C., 2003. Relationship between peak ground acceleration, peak ground velocity, and intensity in Taiwan. Bulletin of the Seismological Society of America, 93(1), 386-396. 